\title{
Experimental and numerical investigation of heat dissipation from an electronic component in a closed enclosure
}

\author{
Bobin Saji George ${ }^{1 *}$, Ajmal M. ${ }^{1}$, Deepu S. R. ${ }^{1}$, Aswin M. ${ }^{1}$, Ribin D. ${ }^{1}$ and Akhil J. ${ }^{1}$ \\ ${ }^{1}$ Department of Mechanical Engineering, Mar Baselios College of Engineering\& Technology, \\ Thiruvananthapuram, Kerala
}

\begin{abstract}
Intensifying electronic component power dissipation levels, shortening product design cycle times, and greater than before requirement for more compact and reliable electronic systems with greater functionality, has heightened the need for thermal design tools that enable accurate solutions to be generated and quickly assessed. The present numerical study aims at developing a computational tool in OpenFOAM that can predict the heat dissipation rate and temperature profile of any electronic component in operation. A suitable computational domain with defined aspect ratio is chosen. For analyzing, "buoyant Boussinesq Simple Foam" solver available with OpenFOAM is used. It was modified for adapting to the investigation with specified initial and boundary conditions. The experimental setup was made with the dimensions taken up for numerical study. Thermocouples were calibrated and placed in specified locations. For different heat input, the temperatures are noted down at steady state and compared with results from the numerical study.
\end{abstract}

Keywords: Heat transfer, OpenFOAM, Boussinesq, Aspect ratio,

\section{Introduction}

The computational power of each electronic component increases drastically leading to shrinking the physical size of the component. Whenever current is passed through a conductor heat is produced in it because of the resistance of the conductor. This will happen as such in the case of electronic component also. In the case of circuit boards, the main point of heat generation is the junction where the components are fixed in the circuit board; at that point the resistance is maximum. Due to the continuous miniaturization of the electronic equipment the area of the component also decreases so the rate of heat dissipation also decreases.

Before the manufacturing of the equipment proper study in the heat generation and what type of cooling system is required should be selected according to the study conducted. In many of the electronic component either natural convection or forced convection technique is chosen for the cooling. In avionic component, the cooling system will be either liquid cooling or cooling by heat pipe. Extended surfaces, which are

\footnotetext{
* Corresponding author: bobin.george@mbcet.ac.in
} 
popularly known as fins, are extensively used in air cooled heat exchangers and electronic component. An insufficient removal of heat can result in temperatures above the equipment operational limits. In these circumstances, the performance, the life and the reliability of the equipment are extremely reduced. During the selection of a cooling technique the environment where the equipment is working should be taken into consideration. The failure rate of the electronic component increases exponentially with temperatures. Without proper design and control, high rate of heat generation result in high operating temperature for electronic equipment, which reduces the safety and reliability

This study deals with the analysis of electronic component in a closed enclosure experimentally and numerically. Here a heater is designed such that it will produce the average heat that electronic component generates. A forced convection technique is used to cool the heater. Thus, the amount of heat dissipated can be studied easily. By varying the flow parameters, different temperature contours are obtained for studying. Numerically the experimental set up is modelled in Open FOAM and analysed.

\section{Literature review}

Peter Rodgers [1] presents that during the analysis of a normal flow (forced convection) through a cavity having low Re value the normal flow modelling technique with CFD is not applicable. By using normal CFD coding the error in result is nearly $35 \%$. For the accurate result shear stress transport $\mathrm{k}-\omega$ model is used. RANS is the most suitable approach for analyzing the equipment heat transfer. Domenico Borello [2] states that for obtaining high and low pressure eddies in a flow Large Eddie Simulation (LES) is used. LES allow predicting the pressure rise capability of the fan and can reproduce the flow features. The vortex pattern occur in the blades are due to the thickness distribution of the section at the roof. GiorgiaNardini [3] states that in a square cavity the natural convection becomes more effective when there is 4 cold squares is located in the vertical wall and 1 hot source at the center. Position of heat source plays a significant role in the case of natural convection. As the $\mathrm{Ra}$ increases the number of recirculation also increases. Also, the velocity will increase with Ra. D Senthilkumar [4] states that whenever the buoyancy force is smaller than the fluid inertial force the increase in fluid inertial force will not make any change in convective heat and mass transfer. So, inertial force of fluid helps to improve the heat and mass transfer if and only if thermal buoyancy force is of same magnitude or greater than fluid inertial force. ArlindoTribess [5] presents the flow over an electronic equipment is on interest, then the superficial generation is the best approach, because it is more conservative. In the other hand, if the concern is with the temperatures on the equipment surfaces, the volumetric generation is a better approach. Wataru Nakayama [6] presents that thermal design of actual component requires a CFD simulation code to be designed. Many factors that are present in the actual component are not considered while making the model. NesreenGhaddar [7] states the quantity of air infiltrating through a porous member do not affect the external flow pattern over the member. Natural convection enhances ventilation at lower wind. So, if a porous member is placed in between a low wind flow and a heat source, the heat source will experience only natural convection and no forced convection until, the wind velocity reaches a significantly high value. So, when modelling, it is important include natural convection along with forced convection for flow velocities $<3$ $\mathrm{m} / \mathrm{s}$. Study showed an increase of $12 \%$ in heat transfer. Peter J Rodgers [8] validated the predictive accuracy of CFD codes for Heat transfer in electronics components. An experimental set up having a standard PCB with 3 general electronic components mounted in various configurations is made and various parameters were measures under specific working conditions. The results obtained were used to validate the codes. Peter J Rodgers 
[9] validated the numerical accuracy of the codes reduced with the increase in complexity of configuration of components on PCB. In case of populated boards, flow models capable of modeling transition were found to be required to capture the entire flow field. Zaghdoudi [10] presents the heat pipe as a medium for heat transfer, it was found that hot spots could be eliminated and the heat was spread better. Using heat pipes the component temperature was reduced significantly. The study was done on AEM (Avionics Electronics Modules) and the limitation for its practical application is the physical design of heat pipe to be accommodated on the small sections between modules. M.A. Hassan [11] presents that, the paper deals with the study of steady state and natural convection of Bingham fluid in a square enclosure discretely heated from bottom wall and symmetrically cooled from side walls. The effects of different values of Bingham number, $\mathrm{Ra}, \operatorname{Pr}$ and heat transfer characteristics inside the enclosure are studied. A correlation of average $\mathrm{Nu}$ as a function of other non-dimensional numbers has been established using the present numerical results. TuncIcoz [12] states the effect of separation distance and pressure drop is significant only in the turbulent case. It is found that as the height of source raises, the heat transfer rate raises due to increase in surface area. Properties of air and water (de-ionized) possess similar trends but among them water has high heat transfer coefficient. $\mathrm{Z}$. Xu [13] validates that to get maximum efficiency, the CPVs should be under a suitable temperature. The rate of increase of efficiency as Re increases is higher at low range of Re values and then get reduced. This is because at low Re values, heat transfer is by forced convection and at high values conduction become dominant. Hakan F Oztop [14] states that, among different geometry shapes, curvilinear shape exerts more control on heat and fluid flow due to natural convection. Heat transfer increases with additional of nanoparticles into the base fluid. Mehmet Arik [15] presents the heat transfer capabilities of both small-scale synthetic and steady jets are studied and found out the value of heat transfer coefficient increases with increasing Re. The distance between jet to heater has more effect on $\mathrm{Nu}$ for steady jets than for synthetic jets. At high Re synthetic jets show 30\% better heat transfer performance and for the same spacing synthetic jet showing 40\% superior heat performance. Yoji Kitamura [16] presents that, as the inclination increases it also enhances the air flow rate. The cooling effect has been improved by inclination of electronic casing for the circulation of air flow inside the casing increases. Mousa M. Mohamed [17] states that, comparatively the effect of air mass flow rates on heat transfer is a positive effect but the effect of channel base temperatures has highly positive effect. This is because as Re increases the $\mathrm{Nu}$ increases and thus increasing heat transfer and also at the same air flow rate the heat transfer coefficient is increased with increasing the channel base temperature. Xiaohong Hao [18] validates the heat transfer and pressure drop in serpentine channel heat sinks with 1800 bends. The study is carried out using a thermal resistance model and also pressure drop within the serpentine channel is derived after considering the effects of bends on pressure variation. Then the same model is experimentally validated by measuring temperature and pressure characteristics of heat sinks with different $\mathrm{Re}$ and different geometric parameters. Finally, the experimental result and the numerically obtained result (using CFD) are compared and validated. Hamid Reza Seyf [19] analyzes the effect of Nanoencapsulated phase change material (NEPCM) slurry on forced convection heat transfer of steady laminar flow past an isothermal square cylinder using a finite volume method (FVM) on collocated grid arrangement. It was found that for both NEPCM slurry and pure water, local and average heat transfer coefficients increases with increasing Re.

\section{Numerical analysis}

The computational 2D domain was created in ICEM CFD. After the geometry creation, surface creation followed by part naming was done such as inlet, outlet etc. the entire 
computational domain was divided into block followed by meshing. Since our region of interest is around the surface of the heating element much finer mesh was created around it. Different bunging laws were applied in order to get the quality mesh. The created mesh was converted into mesh suitable for OpenFOAM. Figure 1 gives the computational domain designed and Figure 2 shows the mesh generated.

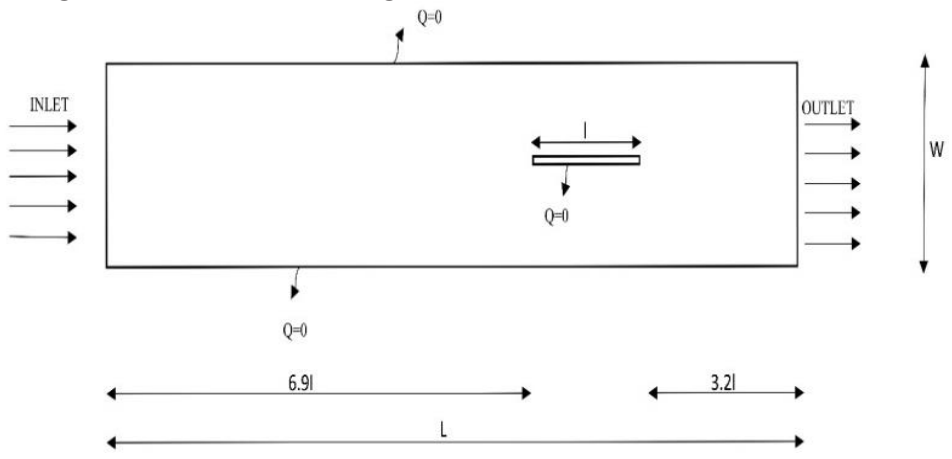

Fig.1. Computational domain

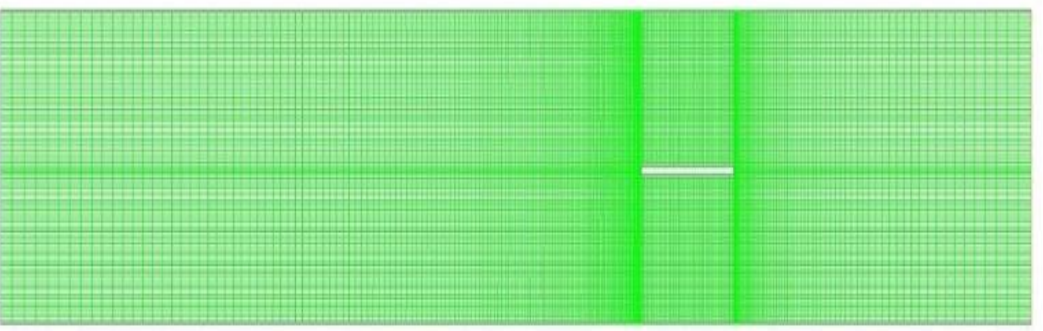

Fig.2. Mesh generated

The domain is designed with an aspect ratio $(\mathrm{L} / \mathrm{W})$ of 6 . The upstream distance was 6.91 and downstream length was 3.21. The area of study was around the heater, in order to reduce the disturbances in the flow the heater was placed at the distance of 6.91. To study the grid independence of the domain, different mesh such as coarse mesh, medium mesh and fine mesh was created for all the power rating and all the velocity. Variation of heat transfer coefficient above the heater is observed for all the cases. The variations of all the cases are shown in the different contours. By analyzing the grid independency mesh with 27460 nodes was selected. For analysis buoyantBoussinesqSimpleFoam solver available with OpenFOAM is used. The mass conservation is given by the equation

$$
\frac{\partial \rho}{\partial t}+\nabla \cdot(\rho u)=0
$$

The momentum conservation is given by the equation

$$
\frac{\partial(\rho u)}{\partial t}+\nabla \cdot(\rho u u)=-\nabla \mathrm{p}+\rho g+\nabla \cdot\left(2 \mu_{\mathrm{eff}} \mathrm{D}(\mathrm{u})\right)
$$

The density $\rho$ in the gravitational term is expressed by the linear function of the temperature, $\mathrm{T}$

$$
\rho \approx \rho_{o}\left[1-\beta\left(T-T_{o}\right)\right]
$$

The effective viscosity $\mu_{\text {eff }}$ is the sum of the molecular and turbulent viscosity and the rate of strain (deformation) tensor $\mathrm{D}(\mathrm{u})$ is defined as

$$
D(u)=\frac{1}{2}\left(\nabla \mathrm{u}+(\nabla \mathrm{u})^{\mathrm{T}}\right)
$$

The energy conservation is given by the equation 


$$
\frac{\partial(\rho e)}{\partial t}+\nabla \cdot(\rho u e)+\frac{\partial(\rho K)}{\partial t}+\nabla \cdot(\rho u K)+\nabla \cdot(p u)=\nabla \cdot\left(\alpha_{e f f} \nabla e\right)+\rho u . g
$$

Cases with varying power dissipation from heater are studied as the power dissipation of electronic component varies from $10 \mathrm{~W}$ to $200 \mathrm{~W}$ for a velocity of range $0.5 \mathrm{~m} / \mathrm{s}$ to $5 \mathrm{~m} / \mathrm{s}$ [9].

\section{Experimental setup}

The test chamber is mainly to enclose the heater into a closed channel of air flow. The entire section is placed on a structure made of $3 / 4$ inch ' $L$ ' section mild steel bar as shown in Figure 3.
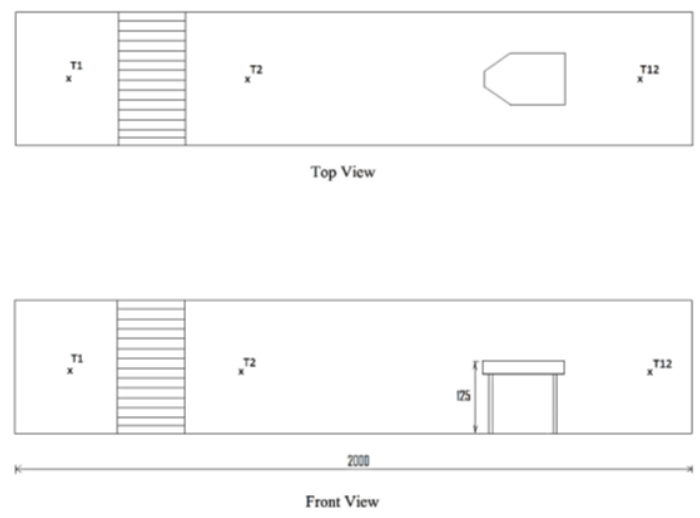

Fig.3. Experimental setup

The function of heater is to simulate an electronic component generating heat $10 \mathrm{w}$ to 200w and the heat generation can be controlled. Nickel-Chromium (Nichrome) wire of area $0.035 \mathrm{~mm} 2$ with thin mica sheet as supporting material is selected as the heater material. Figure 4 shows the heater cross section with thermocouple positions. The heater is placed horizontally on the middle of the test section by supporting it on $3 \mathrm{~mm}$ bolts. A blower isused for air supply, an autotransformer was used to control the supply voltage to the blower thereby controlling its speed and flow velocity. The honeycomb structure is used to straighten airflow. The honeycomb eliminates whatever unevenness with which flow occurs. Uneven turbulent flows can cause unpredictable forces to be experienced and measured in the test section. The less turbulence there is, the better the experimental setup will simulate actual flow conditions. Honeycomb is very efficient at reducing the lateral turbulence, as the flow pass through long and narrow pipes. But the problem with Honeycombs is, it introduces axial turbulence of the size equal to its diameter which restrains the thickness of the honeycomb. To tackle this problem, Screens are introduced as they reduce longitudinal turbulence very efficiently. The honeycomb can be made of hexagonal cells, like normal honeycomb, but it can also be circular or square cells. The honeycomb is normally placed at the very beginning of the wind tunnel. This is because the honeycomb is more effective when the air is at a lower velocity. In this experiment, a honeycomb structure of circular cells, is employed, which is made of straws. Figure 5 shows photograph of actual experimental setup. Smoke is used as the tracer for air flow. The use of smoke as the tracer particle helps to view the path of the flow. Even then, if the field is illuminated in a plane by appropriate masking of the light source it is possible to examine discrete sections or slices of the flow. So, a laser-lens combo illumination setup is used for visualization. 

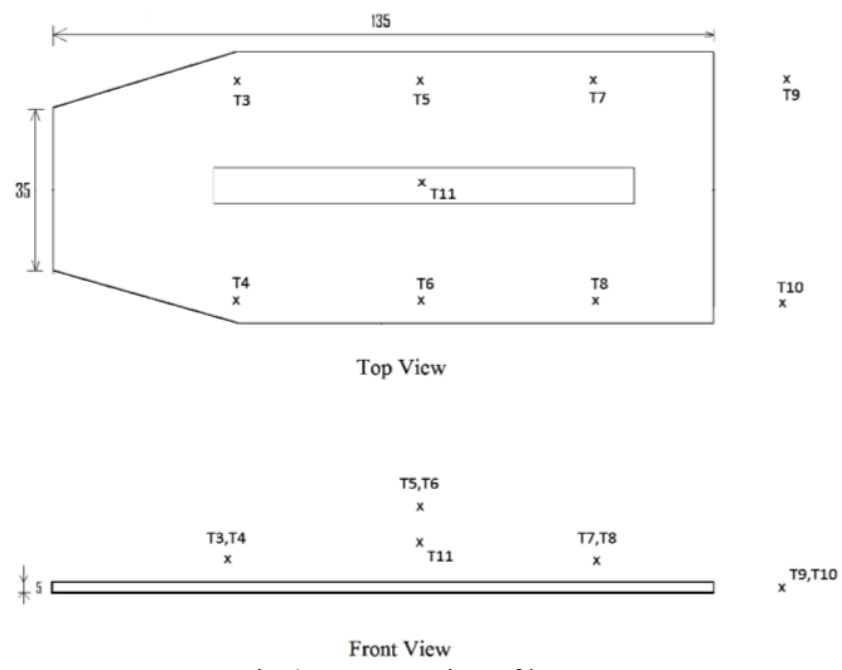

Fig.4. Cross section of heater

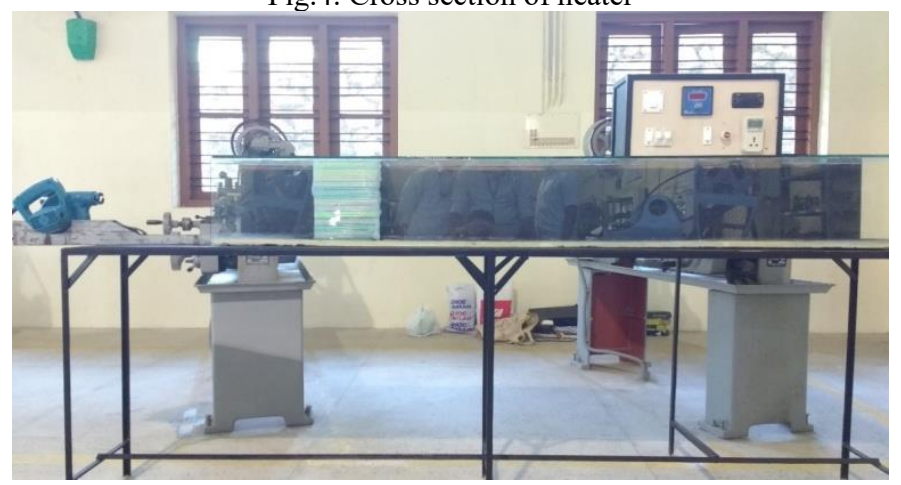

Fig.5. Experimental setup

\subsection{Experimental procedure}

First turn ON the main switch, now turn on the autotransformer switch. Turn the blower autotransformer and using an anemometer the flow velocity is checked. Simultaneously adjust the autotransformer and check flow velocity on anemometer so that the required velocity is obtained. Now turn on the heater switch and adjust the heater autotransformer so that the required power is obtained in the watt meter. Check the ammeter frequently to make sure there is no current over shoot. Check the value of temperature from T1 to T12 at regular intervals of say 10 minutes until steady state is obtained. Once steady state is obtained, the values of temperature from $\mathrm{T} 1$ to $\mathrm{T} 12$ are noted from the digital temperature indicator. Introduce a smoke source at the inlet of the section. Hold the laser and microscope eye piece on the burette stand and focus the light over the heater. Now observing from the front the flow pattern over the heater can be seen.

For finding the value of Convective heat transfer coefficient from the experimental data, Nusselt number needs to be calculated. Nusselt number is calculated using the following correlations:

Dittus-Boelter correlation, $\mathrm{Nu}=0.023 \mathrm{Re}^{0.8} \operatorname{Pr}^{0.4}$ 
Gnielinski's correlation

$$
\begin{gathered}
\mathrm{Nu}_{\mathrm{D}}=\frac{\left(\frac{f}{8}\right)\left(R e_{D}-1000\right) P r}{1+12.7\left(\frac{f}{8}\right)^{\frac{1}{2}}\left(\operatorname{Pr}^{\frac{2}{3}}-1\right)} \\
\quad f=\left(0.79 \ln \left(R e_{D}\right)-1.64\right)^{-2}
\end{gathered}
$$

Boundary layer theory

$$
\begin{aligned}
& \mathrm{Nu}_{\mathrm{L}}=0.453 \times \operatorname{Re}_{\mathrm{L}}{ }^{.5} \times \operatorname{Pr}^{0.333} \\
& \mathrm{Nu}_{\mathrm{L}}=2 \times \mathrm{Nu}_{\mathrm{L}}
\end{aligned}
$$

With the value of Nusselt number, heat transfer coefficient is calculated using the equation

$$
h=\frac{N u * K}{l}
$$

The value of $\mathrm{h}$ agreeing closely with numerical results is chosen.

\section{Results and discussion}

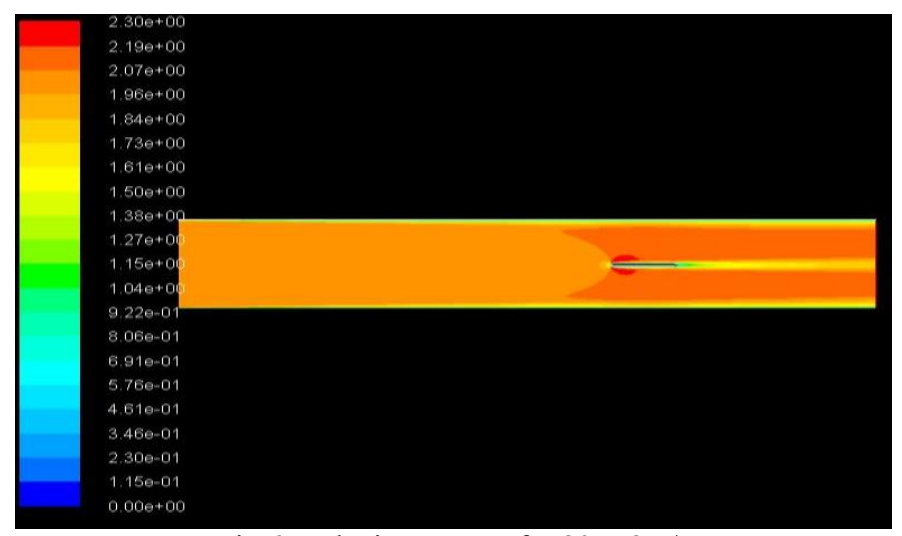

Fig.6. Velocity contour for $80 \mathrm{~W} 2 \mathrm{~m} / \mathrm{s}$

Figure 6 shows the velocity contour for one of the cases analyzed. The velocity is provided at the inlet. Till the left end of the heater the flow is continuous since there is no obstruction to the flow. But when the flow meets the heater the obstruction will happen and a region of low pressure will form which result in a high velocity at the initial portion. Since no slip condition is provided at the top, bottom and walls of the heater the velocity of the fluid layer adjacent to the wall is zero. As the flow progresses through the surface of the heating element a boundary layer formation will occur. The velocity will increase as the flow proceeds over the heater since the density of the air decreases due to the heating of the surface air. Ambient air temperature and steady state surface temperature of the heater is given at the inlet and the surface of the heating element respectively. The fluid layer adjacent to the surface of the heater will have more temperature.. Under low inlet velocity condition there is a chance for the air surrounding the heater to form convection current due to the variation in density. But at the higher velocities the effect of variation in density is negligible. From the contour the air takes away the majority of the heat generated in the heating element. As the heated air moves to the upstream of the duct the temperature of the air will decrease at a small rate. Figure 7 shows the temperature contour after steady state. 


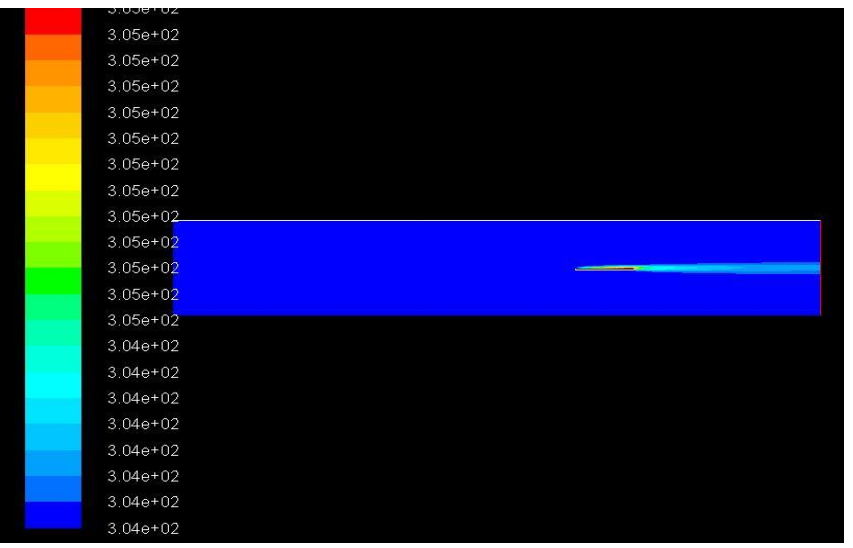

Fig.7. Temperature contour for $80 \mathrm{~W}, 2 \mathrm{~m} / \mathrm{s}$

\begin{tabular}{|c|c|c|c|c|c|}
\hline \multirow{2}{*}{$\begin{array}{c}\text { Velocity } \\
(\mathrm{m} / \mathrm{s})\end{array}$} & \multirow[t]{2}{*}{ Power $(\mathrm{W})$} & \multicolumn{4}{|c|}{ Convective heat transfer coefficient $\left(\mathrm{W} / \mathrm{m}^{2} \mathrm{~K}\right)$} \\
\hline & & Analysis & $\begin{array}{l}\text { Dittus Boelter } \\
\text { correlation }\end{array}$ & $\begin{array}{l}\text { Boundry layer } \\
\text { theory }\end{array}$ & $\begin{array}{l}\text { Gnielinski's } \\
\text { Correlation }\end{array}$ \\
\hline \multirow{6}{*}{0.5} & 10 & 3.348 & 5.12 & 10.358 & 4.816 \\
\hline & 40 & 3.375 & 5.10 & 10.357 & 4.799 \\
\hline & 80 & 3.36 & 5.08 & 10.356 & 4.772 \\
\hline & 120 & 3.613 & 5.05 & 10.356 & 4.741 \\
\hline & 160 & 3.379 & 5.12 & 10.339 & 4.694 \\
\hline & 200 & 3.621 & 5.21 & 10.337 & 4.691 \\
\hline \multirow{6}{*}{1} & 10 & 6.160 & 8.93 & 14.649 & 8.387 \\
\hline & 40 & 6.214 & 8.91 & 14.648 & 8.373 \\
\hline & 80 & 6.177 & 8.88 & 14.647 & 8.347 \\
\hline & 120 & 6.161 & 8.86 & 14.646 & 8.327 \\
\hline & 160 & 6.504 & 8.83 & 14.646 & 8.300 \\
\hline & 200 & 6.482 & 8.79 & 14.646 & 8.269 \\
\hline \multirow{6}{*}{2} & 10 & 11.652 & 15.53 & 20.716 & 14.328 \\
\hline & 40 & 11.717 & 15.51 & 20.715 & 14.313 \\
\hline & 80 & 11.831 & 15.48 & 20.714 & 14.286 \\
\hline & 120 & 11.817 & 15.45 & 20.714 & 14.262 \\
\hline & 160 & 11.290 & 15.40 & 20.713 & 14.218 \\
\hline & 200 & 11.274 & 15.36 & 20.713 & 14.185 \\
\hline
\end{tabular}




\begin{tabular}{|l|l|l|l|l|l|}
\hline \multirow{5}{*}{} & 10 & 26.75 & 32.28 & 32.754 & 29.06 \\
\cline { 2 - 6 } & 40 & 26.95 & 32.27 & 32.753 & 29.05 \\
\cline { 2 - 6 } 5 & 80 & 26.90 & 32.24 & 32.753 & 29.03 \\
\cline { 2 - 6 } & 120 & 27.44 & 32.25 & 32.753 & 29.04 \\
\cline { 2 - 6 } & 160 & 27.67 & 32.22 & 32.752 & 29.01 \\
\cline { 2 - 6 } & 200 & 27.814 & 32.19 & 32.751 & 28.99 \\
\hline
\end{tabular}

Tab.1. Heat transfer coefficients

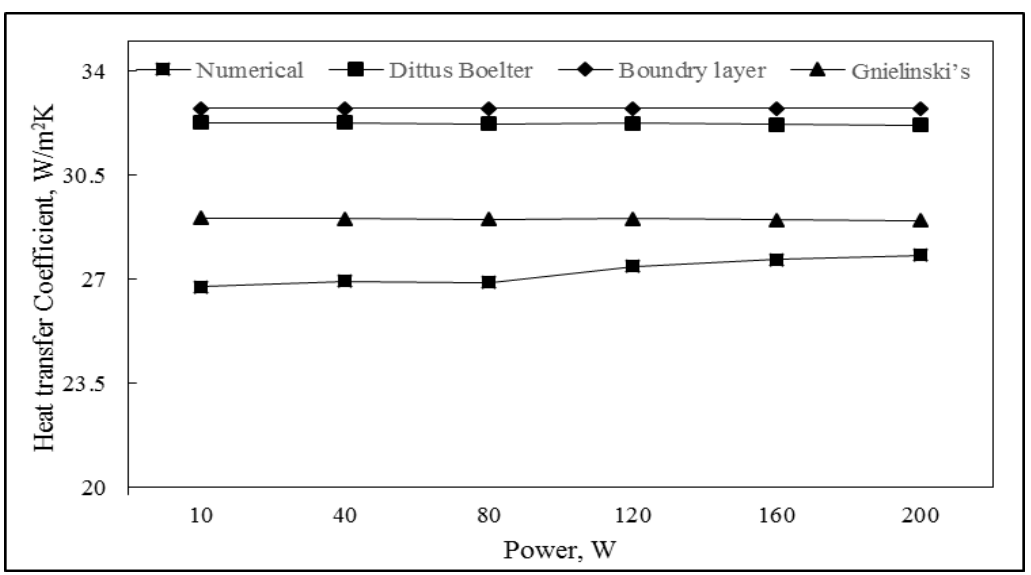

Fig.8. Heat transfer coefficients for $5 \mathrm{~m} / \mathrm{s}$

From Figure 8, it can inferred that, maximum agreement is between numerically obtained value (hanalysis) and value obtained using Gnielinski's correlation. So, value of heat transfer coefficient obtained using Gnielinski's correlation is taken as hexperimental.

From Figure 9 and 10 of convective coefficient for experimental and numerical results, it is seen that the results show a constant decrease in convective coefficient with increase in heater power for all velocities. This can be justified as the heat generated increases, the heater surface temperature also increases and this heats up the surrounding air much faster. So, the temperature difference between the heater surface and ambient air becomes lesser causing the heat transfer rate to decrease with increase in heat generation. Hence it is very curious to note that for a constant flow, the amount of heat dissipated to air decrease with increase in heat generation. Numerical results also show similar trend with experimental results. But for higher velocities numerical results show some fluctuations. This is mainly because of the limitations in the assumptions made during analysis. Friction was not considered for doing the analysis and frictional effects dominates only at higher velocities. At lower velocities, frictional losses are not very dominant. This justifies the fluctuations at higher velocities. Figure 11 shows the comparison between temperature values from thermocouple and the values obtained from simulation for the thermocouple locations. The agreement between the values validates the numerical model. 


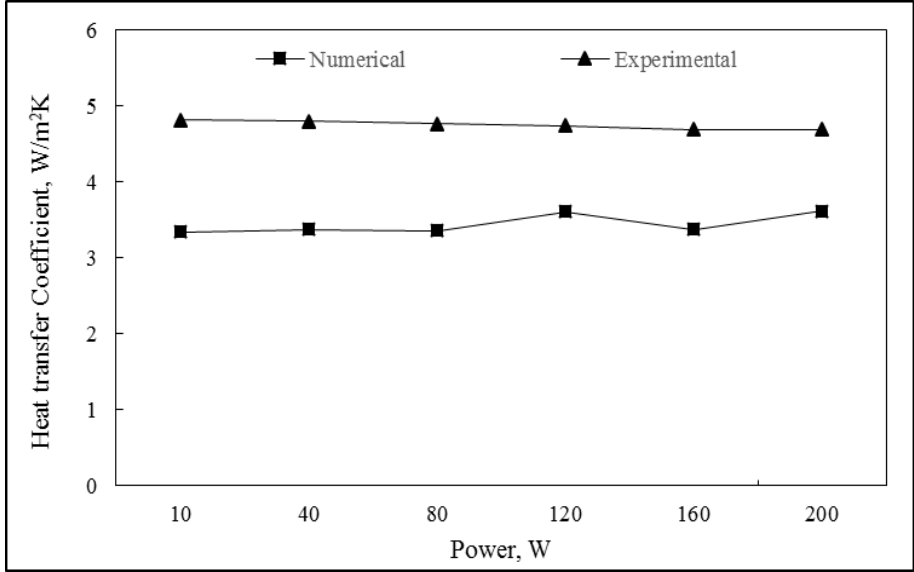

Fig.9. Heat transfer coefficients for $0.5 \mathrm{~m} / \mathrm{s}$

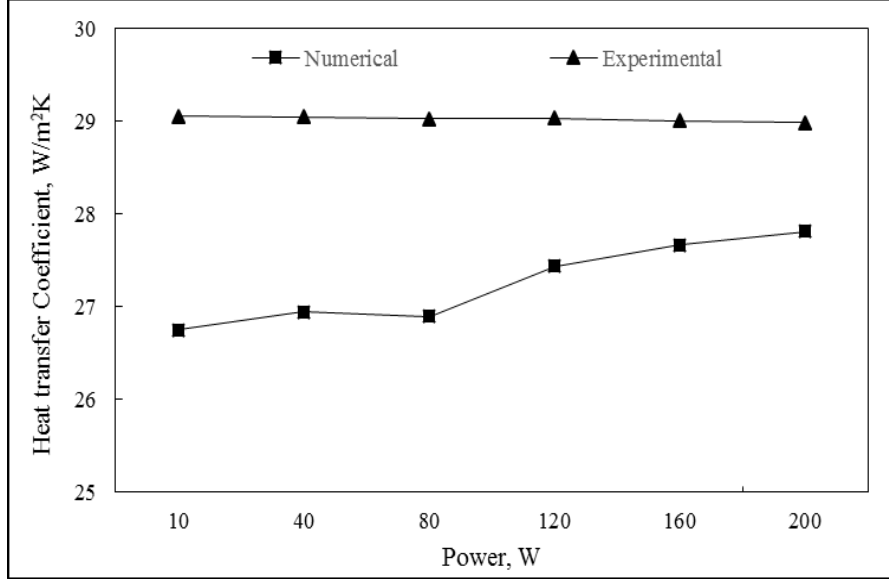

Fig.10. Heat transfer coefficients for $5 \mathrm{~m} / \mathrm{s}$

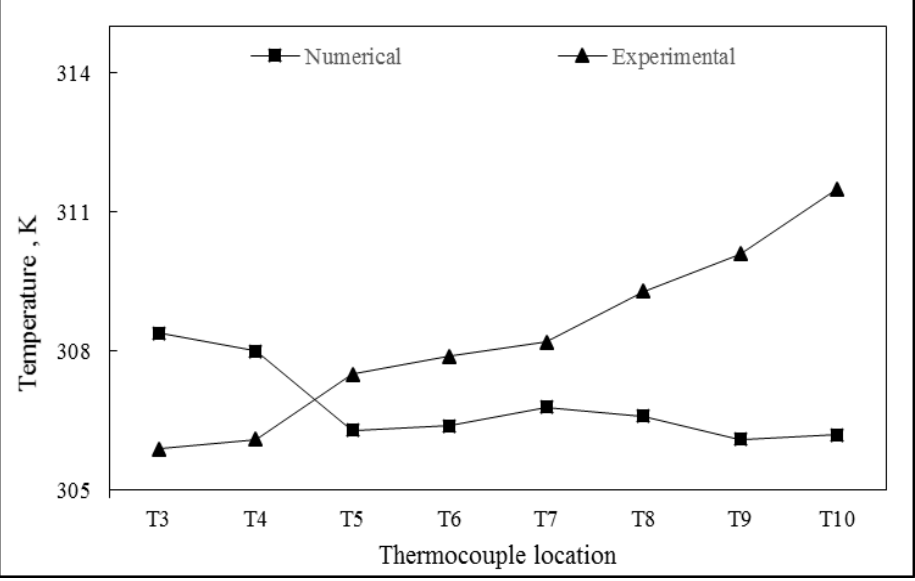

Fig.11. Temperature comparison

Figure 12 shows the comparison between numerical result and the flow visualization observed during experiment. The main feature of the velocity contour is the splitting of the flow stream on hitting the heater and the rising of stream passing above the heater due to density variation caused by the increase in temperature. In experiment also a similar splitting can be observed but some amount of stream is getting diverted to the top and 
bottom walls. This may be due to absorption of heat by the walls (glass and plywood) where as in analysis the walls are perfectly adiabatic and hence no such stream diversion.

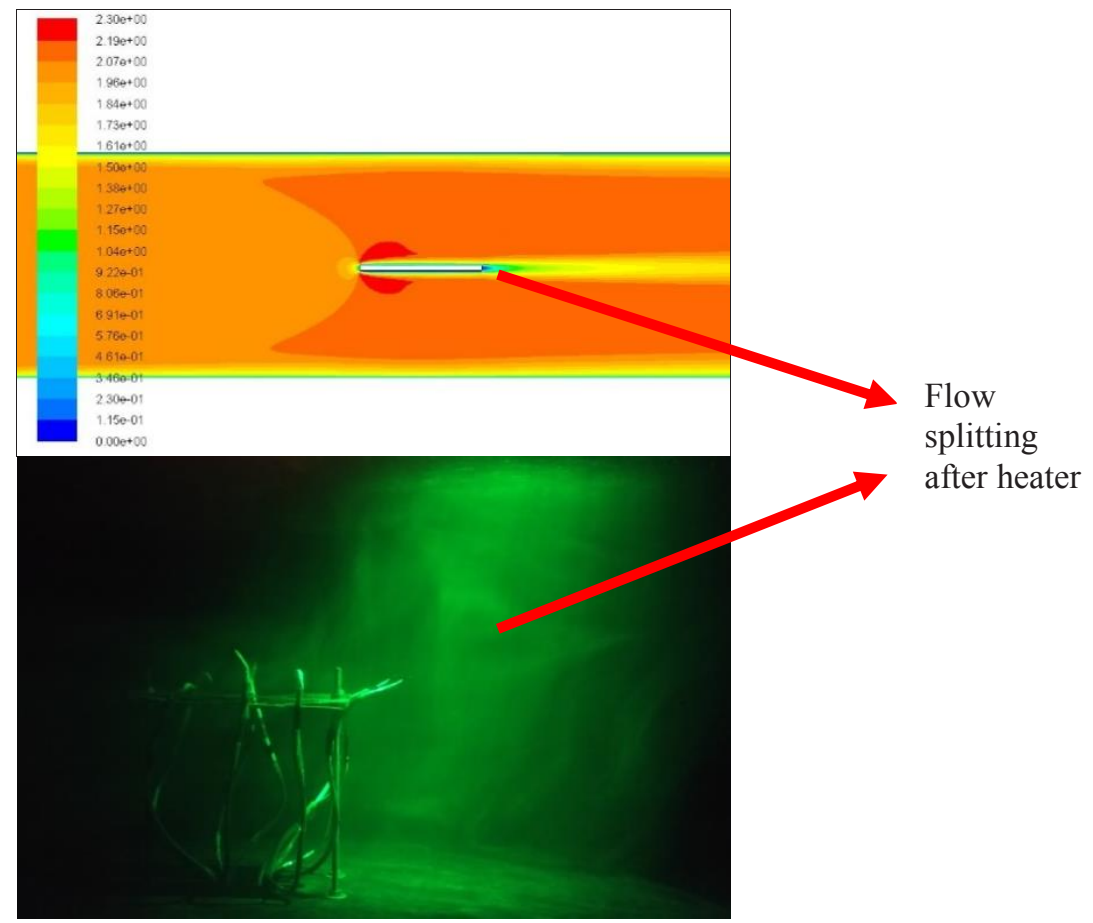

Fig.12. Numerically obtained and smoke visualized velocity contours

\section{Conclusions}

Numerical and experimental study of heat dissipation from electronic components in closed enclosure has been carried out. The numerical model proposed is validated and can be used to predict the value of average convective heat transfer coefficient for a component with a predictive accuracy of $\pm 3 \mathrm{~W} / \mathrm{m} 2 \mathrm{~K}$, which gives an average error of $13 \%$. The experimental results have been computed using a number of correlations of which Gnielinski's Correlation for flow through ducts gave the most agreeing results. The variation in numerical results from the experimental results is mainly due to heat loss from the source to environment during experiment. Heat loss is not considered in numerical modelling.

\section{References}

1. Peter Rodgers, Valerie Eveloy, M.S.J Hashmi, 2005," An investigation into the potential of low Reynolds number Eddy viscosity turbulent flow models to predict electronic component operational temperature" ASME journal of electronic packaging vol.127 pp. 67-75.

2. Domenico Borello, Alessandro Corsini, Giovanni Delibra, Mario Fiorito, Anthony G Sheard, 2013" Large Eddy Simulation of a tunnel ventilation fan" ASME journal of fluid engineering vol.135 pp. 1-9. 
3. Giorgia Nardini, Massimo Paroncini, Raffaella Vitali, 2016," An experimental and numerical analysis of natural convective heat transfer in a square cavity with five discrete heat sources" ASME journal of heat transfer vol.138 pp.1-8.

4. D Senthil Kumar, K Murugesan, Akhilesh Gupta, 2010," Numerical analysis of interaction between inertial and thermosolutal buoyancy forces on convective heat transfer in a lid-driven cavity" ASME journal of heat transfer vol 132 pp.1-11.

5. Arlindo Tribess, Tales Adriano Ferreira, Lorenzzo Victor Schrepel Delmutti, Fernando Stancato, Marcelo Pustelnik, Luis Carlos de Castro Santos, 2005." Analysis of electronic package cooling in an aircraft using CFD" 18th International Congress of Mechanical Engineering

6. Wataru Nakayama, 2013, "Heat conduction in mobile electronic equipment: Study on the effects of some key parameters on heat source temperature based on a 3-layer model" ASME journal of electronic packaging vol. 135 pp.1-5.

7. Nesreen Ghaddar, Kamel Ghali, Mohamad Al-Othmani, Ingvar Holmer, Kalev Kuklane, 2010,"Experimental and theoretical study of ventilation and heat loss from isothermally heated clothed vertical cylinder in uniform flow field" ASME journal of applied mechanics vol.77 pp.1-8.

8. Peter J Rodgers, Valerie C Eveloy, Mark R D Davies,2003, “An experimental assessment of numerical predictive accuracy for electronic component heat transfer in forced Convection-Part 1: Experimental methods and numerical modelling" ASME journal of electronic packaging vol.125 pp.67-75.

9. Peter J Rodgers, Valerie C Eveloy, Mark R D Davies,2003, “An experimental assessment of numerical predictive accuracy for electronic component heat transfer in forced Convection-Part 2: Results and discussion" ASME journals of electronic packaging vol. 125 pp.76-83.

10. M.C Zaghdoudi, A. Teytu., 2000, "Use of heat pipes for Avionic cooling" IEEE, Electronics Packaging Technology Conference pp.425-430

11. M A Hassan, Manabendra Pathak, Mohd. Kaleem Khan,2013, "Natural convection of viscoplastic fluids in a square enclosure" ASME journal of heat transfer vol.135 pp.112.

12. Tunc Icoz, Nitin Verma, Yogesh Jaluria, 2006, "Design of air and liquid cooling system for electronic component using concurrent simulation and experiment" Transaction of the ASME vol128 pp.466-478.

13. Z.Xu, C.Kleinstreuer, 2014, "Computational analysis of nano fluid cooling of high concentrstion photovoltaic cells" ASME journal of thermal science and engineering applications vol.6 pp.1-9.

14. Hakan F.Oztop, Fatih Selimefendigil, Eiyad Abu-Nada, Khaled Al-salem , 2016, "Recent developments of computational methods on natural convection in curve linear spaced enclosures" Journal of thermal engineering pp.693-698.

15. Mehmet Arik, Rajdeep Sharma, Jason Lustbaber, Xin He,2013, "Steady and unsteady air impingement heat transfer for electronics cooling applications" ASME journals of heat transfer vol.135 pp.1-8.

16. Yoji Kitamura, Masaru Ishizuka, 2004, "Chimney effect on natural air cooling of electronic equipment under inclination” ASME journal of electronic packaging vol.126 pp.423-428.

17. Mousa M. Mohamed, Mostafa A.Abd El-Baky, 2013, "Air cooling of mini -channel heat sink in electronic devices" journals of electronic cooling and thermal control pp.49-57. 
18. Xiaohong Hao, Bei Peng, Gongnan Xie, Yi Chen, 2014, “Thermal Analysis and Experimental Validation of Laminar Heat Transfer and Pressure Drop in Serpentine Channel Heat Sinks for Electronic Cooling” ASME Journal of Electronic Packaging, vol.136 pp.1-9.

19. HR Seyf, M Feizbhakshi, 2012, "Computational analysis of nanofluid effects on convective heat transfer enhancement of micro-pin-fin heat sinks", International Journal of Thermal Sciences, vol 58, pp 168-179. 